\title{
СИНТЕЗ НИТРАТОВ ЦЕЛЛЮЛОЗЫ ИЗ ЛЕГКОВОЗОБНОВЛЯЕМОГО НЕДРЕВЕСНОГО СЫРЬЯ
}

\author{
Ю.А. Гисматулина
}

Данная работа направлена на решение проблемы сырьевого обеспечения страны дешевой отечественной целлюлозой для получения многообразной продукции на ее основе, в частности нитратов целлюлозы. В статье рассматриваются два новых перспективных источника целлюлозы: многолетняя ежегодно возобновляемая злаковая культура - мискантус и отходы производства масличного семени - солома льна-межеумка. Из данного сырья азотнокислым способом выделена целлюлоза высокого качества пригодная для этерификации. Синтез нитратов целлюлозы проведен промышленным способом нитрования целлюлозы серно-азотной кислотной смесью. В работе представлены основные характеристики нитратов целлюлозы из легко возобновляемого недревесного сырья. Показана возможность получения из целлюлозы мискантуса и соломы льна-межеумка нитратов иеллюлозы, соответствующих по основным характеристикам промышленным коллоксилинам. Исследование методом ИК-спектроскопии, синтезированных образцов нитратов целлюлозы показано наличие всех основные характеристических частот, соответствующих полосам поглощения нитрогрупп. Методом термогравиметрического анализа установлены высокие температуры разложения нитратов целлюлозы - 210-211 ${ }^{\circ} \mathrm{C}$, что свидетельствует о высокой чистоте полученных продуктов. Методом ЯМР ${ }^{13} \mathrm{C}$-спектроскопии выявлено совпадение большинства химических сдвигов нитратов целлюлозы из мискантуса и соломы льна-межеумка, характерных для 6 - мононитроцеллюлозы, 2,6 - динитроцеллюлозы, 3,6 - динитроцеллюлозы, 2,3,6 - тринитроцеллюлозы хлопковых нитратов целлюлозы.

Ключевые слова: мискантус, солома льна-межеумка, азотнокислый способ, целлюлоза, нитрование, стабилизация, нитраты целлюлозы

\section{ВВЕДЕНИЕ}

Среди широкого круга полимеров нитраты целлюлозы (НЦ) прочно удерживают одну из ведущих позиций и имеют огромное практическое значение в оборонной и гражданской отраслях промышленности. Многообразие областей применения НЦ определяются их специфическими свойствами. Высокая механическая прочность, возможность перевода в пластифицированное состояние, хорошая растворимость и совместимость с доступными пластификаторами определяют использование НЦ в качестве энергетической основы нитроцеллюлозных порохов, ракетных топлив, компонента лакокрасочных продукции [13], для изготовления оптических прозрачных пленок, биологических индикаторов, полупроницаемых мембран, селективных сорбентов, нитролаков специального назначения [4].

Основным сырьем для производства НЦ является хлопковая целлюлоза ГОСТ 595-79, древесная целлюлоза в форме рулонной бумаги, «папка» и в виде жгутиков [2]. Наряду с ними используют и льняную целлюлозу [5].

В настоящее время отечественные производители продукции на основе целлюлозы, в частности при изготовлении НЦ сталкиваются с проблемой сырьевого обеспечения, связанной с сокращением объемов производств всех видов целлюлоз, удорожанием стоимости древесного сырья и отсутствием собственной хлопковой целлюлозы, что привело к монопольному росту цен даже на хлопок низкого качества [6].

Данную проблему можно решить путем использования в качестве источника целлюлозы легко возобновляемое не древесное сырье. Преимуществами травянистых растений являются высокая урожайность и низкая затраты на возделывание. Они выращиваются во многих регионах РФ и через несколько месяцев после посадки готовы к технологическому использованию. Более того, солома злаковых культур, льна-кудряша, льнамежеумка, рапса и др. не находит квалифицированного применения, а сжигается на полях, либо запахивается, что приводит к дополнительным затратам. Важно отметить, что с 1 Га посевов травяных культур собирают в 5-8 раз больше, чем с одного гектара леса [6].

Возделывание однолетних растений, содержащих целлюлозу, обозначено семеркой 


\section{Ю.А. ГИСМАТУЛИНА}

развитых Европейских стран как одна из 20 приоритетных задач XXI века [6].

Таким образом, с целью решения проблемы сырьевого обеспечения ученые во всем мире уделяют повышенное внимание таким травянистым растениям, как - лен, рапс, донник, люцерна, подсолнечник, конопля, камыш, кукуруза, пшеница, овес и др., отличающихся высокой урожайностью и высоким потенциалом выращивания [6-14] и отходам переработки сельскохозяйственных культур (солома, стебли хлопчатника хлопковая шелуха, кукурузная кочерыжка, подсолнечная лузга, рисовая шелуха и др.) [15-18].

Имеется большое количество работ по успешному получению НЦ из волокна льнадолгунца [5, 19-21]. Установлена возможность использования НЦ на основе льняного сырья в качестве компонента пороха, не уступающего по характеристикам пороху из хлопковой целлюлозы $[5,20]$. Имеются разработки по получению НЦ с массовой долей азота 10,50-13,06 \% из костры льна [22]. Авторы [23] экспериментально показали возможность получения НЦ с массовой долей азота 13,10-13,30 \% нитрованием целлюлозы из технической конопли серно-азотной кислотной смесью. В работах [24, 25] показана возможность получения азотнокислых эфиров целлюлозы с содержанием азота 12,40 $13,40 \%$ на основе облагороженной пеньковой целлюлозы. Получены НЦ, содержащие свободную гидроксильную группу из соломы пшеницы [26]. Известны исследования по синтезу НЦ из плодовых оболочек овса с массовой долей азота в диапазоне 11,76$12,55 \%$ и растворимостью в спиртоэфирной смеси 93-97 \% [27]. В Венгрии ведутся работы по получению НЦ из эспарто [28].

Кроме того, проводятся исследования по получению НЦ из промышленных и бытовых отходов [29] (массовая доля азота 10,50$13,06 \%)$, различного лигноцеллюлозного сырья (древесины и ее отходов, однолетних растений) [30] и наноцеллюлозы [31].

Таким образом показана актуальность исследований по переработке легковозобновляемого недревесного сырья в НЦ.

Значительный интерес для получения НЦ представляют собой такие перспективные источники целлюлозы, как мискантус (М) и солома льна-межеумка (C). М - это многолетняя злаковая культура с высоким ежегодным приростом биомассы 10-15 т/га/год в течение 15-25 лет с низкими требованиями к условиям выращивания [7, 32]. С - это отходы производства масличного семени, окупа- емые производимой продукцией, по утилизации которых нет готовых решений [33].

Целью работы являлся синтез НЦ с основными характеристиками, соответствующими промышленным коллоксилинам из легковозобновляемого недревесного сырья - М и C.

\section{ЭКСПЕРИМЕНТАЛЬНАЯ ЧАСТЬ}

Объектами исследования являлись М сорта Сорановский (урожай 2015 г., возраст плантации 5 лет, г. Бийск, Россия) [32] и общая партия С урожаев 2011-2014 гг. (Алтайский край) [33]. Химический состав сырья был определён по стандартным методикам анализа растительного сырья [34].

Перед проведением исследований сырье было измельчено ножницами. Целлюлозу из М и С выделяли азотнокислым способом, заключающимся в последовательной обработке сырья разбавленными растворами азотной кислоты и гидроксида натрия [32, 33, 35]. Качество целлюлозы определяли стандартными методами анализа целлюлозы [34].

Синтез НЦ проводили нитрованием целлюлозы из М и С серно-азотной кислотной смесью с массовой долей воды - $14 \%$ в условиях получения растворимых в спитроэфирной смеси НЦ [36, 37]. Модуль нитрования составлял 1:25. Промытые до нейтральной реакции образцы НЦ стабилизировали при непрерывном перемешивании по схеме: варка в воде в течение 1 ч при 80-90 ${ }^{\circ} \mathrm{C}$, автоклавирование в 0,3\%-м растворе азотной кислоты при температуре $120-130{ }^{\circ} \mathrm{C}$ в течение 2-5 ч, варка в 0,03 \%-м растворе карбоната натрия в течение 3 ч при 80-90 ${ }^{\circ} \mathrm{C}$, затем снова в воде в течение 1 ч при 80-90 ${ }^{\circ} \mathrm{C}$. Высушенные при температуре $(100 \pm 5){ }^{\circ} \mathrm{C}$ образцы НЦ анализировали стандартными методами, принятыми в отрасли [38].

ИК-спектры образцов НЦ регистрировали на спектрометре «Инфралюм-801» (Россия) в диапазоне частот 4000-500 см-1. Для съемки спектров прессовали таблетки в бромиде калия в соотношении $\mathrm{HЦ}: \mathrm{KBr}=1: 150$.

Термогравиметрический анализ (ТГА) образцов НЦ проводили на термогравиметрическом анализаторе DTG-60 (Япония) в следующих условиях: масса навески 0,5 мг, скорость нагрева $10{ }^{\circ} \mathrm{C} / \mathrm{Mин,} \mathrm{максимальная}$ температура $350^{\circ} \mathrm{C}$, среда инертная - азот.

Образцы НЦ были исследованы методом ЯМР ${ }^{13} \mathrm{C}$-спектроскопии на ЯМРспектрометре Bruker AM 400 (Германия) при $60{ }^{\circ} \mathrm{C}$ с рабочей частотой 100.61 МГц. 


\section{РЕЗУЛЬТАТЫ И ОБСУЖДЕНИЕ}

Химический состав М и С, направленных для выделения целлюлозы и синтеза НЦ: целлюлоза по Кюршнеру -53,1 \% и 55,6 \%; кислотонерастворимый лигнин - 22,0 \% и $24,5 \%$; пентозаны - 21,0 \% и 11,1 \%; жировосковая фракция - 4,90 \% и 2,44 \%; зола $5,87 \%$ и 3,20 \%, соответственно.
Из данного сырья азотнокислым способом были получены образцы целлюлозы. Выход целлюлозы в пересчете на сырье составил из М - $25 \%$ из С - $24 \%$. В таблице 1 представлены показатели качества образцов целлюлозы, полученных азотнокислым способом, из М и С.

Таблица 1 - Показатели качества образцов целлюлозы, полученных азотнокислым способом, из М и С

\begin{tabular}{|l|c|c|c|c|c|}
\hline $\begin{array}{c}\text { Целлюлоза } \\
\text { из }\end{array}$ & $\begin{array}{c}\text { а-целлюлоза, } \\
\%\end{array}$ & Зола, \% & Лигнин, \% & $\begin{array}{c}\text { Пентозаны, } \\
\%\end{array}$ & $\begin{array}{c}\text { Степень } \\
\text { полимеризации }\end{array}$ \\
\hline $\mathrm{M}$ & 94,2 & 0,11 & 0,7 & 0,7 & 1180 \\
\hline $\mathrm{C}$ & 88,3 & 0,31 & 1,5 & 0,8 & 780 \\
\hline
\end{tabular}

Образцы целлюлозы из легковозобновляемого недревесного сырья характеризуются достаточно высоким качеством: массовая доля а-целлюлоз - 88,3-94,2 \%, степень полимеризации 780-1180, суммарное содержание нецеллюлозных компонентов - 1,512,61 \%. Образец целлюлозы из С несколько уступает по качеству целлюлозе из М, в первую очередь более низкими массовой долей и степенью полимеризации, что связано с природными особенностями С, связанными с высоким содержанием низкомолекулярной фрракции целлюлозы в сырье.
Известно, что к целлюлозе для нитрования предъявляются высокие требования: массовая доля а-целлюлозы не менее 92 \%, массовая доля лигнина не более $0,5 \%$, зольность не более 0,3 \% [2, 3]. Несмотря на то, что образцы целлюлозы из исследуемого в работе сырья несколько уступают данным требованиям в научно-исследовательских целях, было проведено нитрование образцов целлюлозы из М и С. В таблице 2 представлены выход и характеристики, синтезированных НЦ из целлюлозы М и С и справочные данные промышленных коллоксилинов.

Таблица 2 - Выход и характеристики, синтезированных НЦ из целлюлозы М и С и справочные данные промышленных коллоксилинов

\begin{tabular}{|c|c|c|c|c|}
\hline $\begin{array}{c}\text { Наименование } \\
\text { образца }\end{array}$ & $\begin{array}{c}\text { Массовая } \\
\text { доля } \\
\text { азота, \% }\end{array}$ & $\begin{array}{c}\text { Вязкость } \\
2 \% \text { раствора } \\
\text { в ацетоне, мПа·с }\end{array}$ & $\begin{array}{c}\text { Растворимость в } \\
\text { спиртоэфирной } \\
\text { смеси, \% }\end{array}$ & $\begin{array}{c}\text { Зола, } \\
\%\end{array}$ \\
\hline $\begin{array}{c}\text { НЦ М № } 1 \\
\left.\text { А (2 ч; } 130{ }^{\circ} \mathrm{C} ; 0,3 \text { \%-ный } \mathrm{HNO}_{3}\right)\end{array}$ & 12,07 & 15,2 & 98 & 0,42 \\
\hline $\begin{array}{c}\text { НЦ М № } 2 \\
\mathrm{~A}\left(5 \text { ч; } 130{ }^{\circ} \mathrm{C} ; 0,3 \text { \%-ный } \mathrm{HNO}_{3}\right)\end{array}$ & 12,09 & 7,0 & 98 & 0,39 \\
\hline НЦ C & 12,19 & 15,7 & 98 & 0,57 \\
\hline $\begin{array}{c}\text { НЦ C } \\
\left.\text { A (2 ч; } 120{ }^{\circ} \mathrm{C} ; 0,3 \text { \%-ный } \mathrm{HNO}_{3}\right)\end{array}$ & 12,20 & 5,3 & 98 & 0,52 \\
\hline Коллоксилин «Н» & $\begin{array}{l}11,85- \\
12,29\end{array}$ & $8,5-15,8$ & не менее 98 & 0,15 \\
\hline $\begin{array}{c}\text { Лаковый средневязкий } \\
\text { коллоксилин (CB) }\end{array}$ & $\begin{array}{l}11,91- \\
12,29\end{array}$ & $3,8-8,4$ & не менее 98 & 0,15 \\
\hline
\end{tabular}

Примечание: А - автоклавированный образец.

Из табличных данных следует, что несмотря на высокое содержание остаточного лигнина в образцах целлюлозы синтез НЦ прошел успешно. Высокая растворимость в спиртоэфирной смеси НЦ со средними значениями вязкости свидетельствует об успеш- ном нитровании исходной целлюлозы с образованием однородного образца НЦ.

Установлено, что из целлюлозы М можно получить НЦ, соответствующие по основным характеристикам разным маркам промышленных коллоксилинов, в частности кол- 


\section{Ю.А. ГИСМАТУЛИНА}

локсилину «Н» и лаковому средневязкому коллоксилину. Вязкость 2 \%-ного раствора НЦ из М в ацетоне при проведении стабилизации образца без стадии автоклавирования значительно превышает требуемый диапазон вязкости промышленных коллоксилинов и составляет $56 \mathrm{мПа \cdot с.} \mathrm{Ввиду} \mathrm{более} \mathrm{низкой}$ вязкости исходной целлюлозы С из нее можно получить НЦ, соответствующие основным характеристикам коллоксилина «Н», в том числе и по вязкости 2 \%-ного раствора НЦ в ацетоне - 15,7 мПа.с. Введение стадии автоклавирования позволяет получить из НЦ С образец НЦ, соответствующий основным характеристикам лаковому средневязкому коллоксилину. Показано, что введение стадии автоклавирования позволяет получить из легковозобновляемого недревесного сырья НЦ, соответствующие промышленным коллоксилинам. Таким образом меняя режимы автоклавирования можно получить НЦ в широком диапазоне свойств.

Поскольку образцы НЦ из М и С по показателям качества близки к промышленным коллоксилинам, то можно предположить, что они могут найти применение как для производства лакокрасочной продукции и т.п., так и для производства баллиститных порохов.

Методом ИК-спектроскопии образцов НЦ из М и С показано наличие всех основные характеристических частот: 2557-2558, 16551657, 1276-1277, 827-828, 745-747, 678-686 $\mathrm{cm}^{-1}$, соответствующих полосам поглощения нитрогрупп [39].

Методом ТГА установлены высокие температуры разложения синтезированных НЦ 210-211 ${ }^{\circ} \mathrm{C}$, что свидетельствует о высокой чистоте полученных продуктов [40].

Методом ЯМР ${ }^{13} \mathrm{C}$-спектроскопии выявлено совпадение большинства химических сдвигов НЦ из М и С, характерных для 6 мононитроцеллюлозы, 2,6 - динитроцеллюлозы, 3,6 - динитроцеллюлозы, 2,3,6 - тринитроцеллюлозы хлопковых НЦ [39].

\section{выводы}

Синтезированы НЦ из легковозобновляемого недревесного сырья - М и С с основными характеристиками соответствующими промышленным коллоксилинам, а именно: массовая доля азота - 12,07-12,20 \%; вязкость 2 \%-ного раствора в ацетоне - 5,315,7 мПа·с; растворимость в спиртоэфирной смеси - $98 \%$.

Работа выполнена при использовании оборудования Бийского регионального цен- тра коллективного пользования СО РАН (ИПХЭТ СО РАН, г. Бийск).

Работа выполнена при фринансовой поддержке РФФИ в рамках научного проекта № 16-33-00232 «мол_а».

\section{СПИСОК ЛИТЕРАТУРЫ}

1. Роговин, 3.А. Химия целлюлозы [Текст] / 3.А. Роговин. - М.: Химия, 1972. - 520 с.

2. Жегров, Е.Ф. Химия и технология баллиститных порохов, твердых ракетных и специальных топлив: в 2-х т [Текст] / Е.Ф. Жегров, Ю.М. Милехин, Е.В. Берковская. - Технология: монография. - М.: РИЦ МГУП им. И. Федорова, 2011. - Т.2. - С. $35-101$.

3. Фиошина, М.А. Основы химии и технологии порохов и твердых ракетных топлив: учебное пособие [Текст] / М.А. Фиошина, Д.Л. Русин. М.: РХТУ им. Д.И. Менделеева, 2001. - 316 с.

4. Валишина, 3.Т. Создание системы управления процессами формирования свойств нитратов целлюлозы [Текст] / З.Т. Валишина, А.В. Косточко, О.Т. Шипина, И.Н. Ахмадуллин // Вестник Казанского технологического университета. - 2014. - T. 17, № 14. - С. 97-100.

5. Григорова, С.И. Лен в пороховой промышленности [Текст] / С.И. Григорова. - М.: ФГУП «ЦНИИХМ», 2012. - 248 c.

6. Марченко, Г.Н. Структурно-химические свойства целлюлозы и ее аналогов. Новые источники сырья, методы их переработки [Текст] / Г.Н. Марченко, О.К. Нугманов, Р.И. Шакиров, Р.Я. Дербердеев. - Казань: «Печать-Сервис XXI век», 2017. -293 c.

7. Shumny, V.K. A new form of Miscanthus (Chinese silver grass, Miscanthus sinensis - Andersson) as a promising source of cellulosic biomass [Text] / V.K. Shumny, S.G. Veprev, N.N. Nechiporenko, T.N. Goryachkovskaya, N.M. Slynko, N.A. Kolchanov, S.E. Peltek // Advances in Bioscience and Biotechnology. - 2010. - V. 1. - P. 167-170.

8. Григорьева, Н.П. Технология получения целлюлозы из травянистых растений и ее свойства [Текст] / Н.П. Григорьева, О.К. Нугманов, Д.С. Нусинович, В.Ф. Сопин, Н.А. Лебедев // Вестник Казанского технологического университета. - 2011. - № 3. - C. 165-168.

9. Вураско, А.В Технология получения целлюлозы из недревесного растительного сырья [Текст] А.В. Вураско, А.Р. Минакова, Б.Н. Дрикер, В.П. Сиваков, А.М. Косачева // Химия растительного сырья. - 2010. - №2. - С. 165-168.

10. Шипина, О.Т. ИК-спектроскопические исследования целлюлозы из травянистых растений [Текст] / О.Т. Шипина, М.Р.Гараева, А.А. Александров // Вестник Казан. технол. ун-та. - 2009. -№6. C. $148-152$.

11. Артемов, А.В. Льняной комплекс России: наука и практика, проблемы и перспективы [Текст] / А.В. Артемов, С.В. Фролов // Текстильная промышленность. - 2005. - № 10. - С. 98.

12. Титов, В.А. Получение целлюлозы из льняного сырья с использованием плазмохимичеПОЛЗУНОВСКИЙ ВЕСТНИК № 12018 
ской обработки [Текст] / В.А. Титов, В.Г. Стокозенко, Ю.В. Титова, А.П. Морыганов. // Химия высоких энергий. - 2015. - Т. 49, № 6. - С. 500-504.

13. Торгашов, В.И. Сравнительное исследование условий выделения, морфологии и свойств целлюлозы из стеблей злаковых и масличных культур [Текст] / В.И. Торгашов, Е.В. Герт, О.В. Зубец, Ф.Н. Капуцкий. // Химия растительного сырья. - 2009. - №4. - С. 45-54.

14. Jung, S.-J. Comparison of lignin, cellulose, and hemicellulose contents for biofuels utilization among 4 types of lignocellulosic crops [Text] / S.-J. Jung, S.-H. Kim, I.-M. Chung. // Biomass and Bioenergy. $-2015 .-$ V. 83. - P. 322-327.

15. Кузнецов, Б.Н. Делигнификация соломы пшеницы смесью уксусной кислоты и пероксида водорода в присутствии сернокислотного катализатора [Текст] / Б.Н. Кузнецов, В.Г. Данилов, И.Г. Судакова, О.В. Яценкова, Н.И. Гарынцева, Е.Ф. Ибрагимова. // Химия растительного сырья. 2009. - №4. - C. 39-44.

16. Вураско, А.В. Ресурсосберегающая технология получения целлюлозы при переработке отходов сельскохозяйственных культур [Текст] / А.В. Вураско, А.Р. Галимова (Минакова), Б.Н. Дрикер // Целлюлоза. Бумага. Картон. - 2007. - №1. C. $16-19$.

17. Пен, Р.3. Делигнификация пшеничной соломы пероксосоединениями [Текст] / Р.З. Пен, Н.В. Каретникова, И.А. Вшивкова, В.Р. Пен // Фундаментальные исследования. - №6. - 2013. - С. 855858.

18. Hu, F. Pretreatment and lignocellulosic chemistry [Text] / F. Hu, A. Ragauskas // Bioenergy Research. - 2012. - № 5. - P. 1043-1066.

19. Пономарев, Б.А. Влияние продуктов гидролиза льняной целлюлозы, нитроцеллюлозы и негидролизуемых примесей на технологические показатели производства нитратов целлюлозы и композиций на их основе [Текст] / Б.А. Пономарев, Т.А. Беликова, Д.Л. Русин, Я.К. Абрамов // Химическая промышленность сегодня. - 2010. - № 10. C. $19-25$

20. Валишина, 3.Т. Исследование структуры целлюлозы из пенькового волокна и нитрата целлюлозы на ее основе [Текст] / 3.Т. Валишина, Г.Н. Галиуллина, Е.С. Петров, Н.И. Наумкина, А.В. Косточко // Вестник Казанского технологического университета. - 2015. - Т. 18, № 13. - С. 149-152.

21. Голубев, А.Е. Изучение кинетики пластифрикации пенькового и льняного нитратов целлюлозы / А.Е. Голубев, Н.Г. Ибрагимов, И.П. Иванова, Т.Э. Субботина, И.О. Городнев // Российский химический журнал. - 2016. - Т. LX, № 1. - С. 85- 93.

22. Ефанов, М.В. Окислительное нитрование костры льна [Текст] / М.В. Ефанов, О.А. Панченко, А.В. Забелина // Химия растительного сырья. 2004. - №3. - C. 95-97.

23. Валишина, 3.Т. Структура и свойства новых типов азотнокислых эфиров целлюлозы [Текст] / З.Т. Валишина, А.В. Косточко, О.Т. Шипина, Р.Ф. Гатина, Ю.М. Михайлов // Вестник Казанского технологического университета. 2010. № 9. C. $281-290$.
24. Валишина, З.Т. Исследование свойств азотнокислых эфиров целлюлозы на основе пеньковой целлюлозы [Текст] / Валишина 3.Т., Иванова А.В., Мухаметшин Б.Ф., Александров А.А., Косточко А.В. // Вестник Казанского технологического университета. - 2016. - Т. 19, № 18. - С. 65-68.

25. Косточко, А.В. Структурно-химические аспекты формирования свойств азотнокислых эфиров целлюлозы [Текст] / Косточко А.В., Валишина 3.Т., Шипина О.Т. // Пластические массы. -2011. № 11 . - C. 56-61.

26. Титова, О.И. Нитрование соломыв пшеницы [Текст] / О.И. Титова, Т.В. Баринова, О.А. Панченко // Пластические массы. - 2009. - № 2. C. $34-36$.

27. Якушева, А.А. Нитраты целлюлозы из нового источника целлюлозы - плодовых оболочек овса [Текст] / А.А. Якушева // Фундаментальные исследования. - 2014. - № 8-2. - С. 360-364.

28. Trache, D.I. Physicochemical properties of microcrystalline nitrocellulose from Alfa grass fibres and its thermal stability [Text] / D.I Trache, K. Khimeche, A. Mezroua, M. Benziane // J Therm Anal Calorim. - 2016. - № 124. - P. 1485-1496.

29. Рогова, Н.С. Нитраты целлюлозы из промышленных и бытовых отходов [Текст] / Н.С. Рогова, М.Р. Гараева, О.Т. Шипина // Вестник Казанского технологического университета. - 2010. - № 9. c. 131-135.

30. Панченко, О.А. Влияние предобработки лигноцеллюлозного сырья на свойства нитратов целлюлозы [Текст] / О.А. Панченко, О.А. Напилкова // Ползуновский вестник. - 2015. - Т. 2, № 4. C. 117-119.

31. Петров, В.А. Получение и свойства нанофибрилярных нитратов целлюлозы [Текст] / В.А. Петров, Н.В. Аверьянова, М.Р. Гибадуллин, И.А. Хамматов, Н.М. Сибгатуллина, И.Р. Бикмухаметов // Вестник Казанского технологического университета. - 2014. - T. 17, № 14. - С. 115-117.

32. Gismatulina, Yu.A. Chemical composition of five Miscanthus sinensis harvests and nitric-acid cellulose therefrom [Text] / Yu.A. Gismatulina, V.V. Budaeva. // Industrial Crops and Products. - 2017. - Vol. 109. - P. 227-232.

33. Гисматулина, Ю.А. Получение целлюлозы азотнокислым способом напрямую из соломы льна-межеумка [Текст] / Гисматулина Ю.А. // Ползуновский вестник. - 2014. - № 3. - С. 160-163.

34. Оболенская, А.В. Лабораторные работы по химии древесины и целлюлозы [Текст] / А.В. Оболенская, 3.П. Ельницкая, А.А. Леонович. - М.: Экология, 1991. - 320 с.

35. Гисматулина, Ю.А. Разработка рациональных условий азотнокислого способа получения целлюлозы из мискантуса [Текст] / Гисматулина Ю.А. // Фундаментальные исследования. 2017. - № 10-2. - C. 189-193.

36. Gismatulina, Yu. A. Nitric acid preparation of cellulose from miscanthus as a nitrocellulose precursor [Text] / Yu.A. Gismatulina, V.V. Budaeva, G.V. Sakovich // Russian Chemical Bulletin. - 2015. - Vol. 64, No. 12. - P. 2949-2953. 


\section{Ю.А. ГИСМАТУЛИНА}

37. Gismatulina, Yu. A. Cellulose nitrates from intermediate flax straw [Text] / Yu.A. Gismatulina, V.V. Budaeva, G.V. Sakovich // Russian Chemical Bulletin. - 2016. - № 12. - Vol. 65, No. 12. - P. 2920-2924.

38. Петров, А.И. Получение и анализ нитратов целлюлозы: лабораторный практикум [Текст] / А.И. Петров, Н.В. Баранова, Н.Н, Никитина. - Казань: Изд-во Казан. гос. технол. ун-та, 2003. - 144 c.

39. Новый справочник химика и технолога. Сырье и продукты промышленности органических и неорганических веществ [Текст] / Ч. ІІ. - СПб. 2006. - 916 c.

40. Коваленко, В.И. Строение, синтез и термическое разложение нитратов целлюлозы [Текст]
/ В.И. Коваленко, Г.Н. Марченко, Г.М. Храпковский, А.Г. Шамов. - М. - 2012. - 396 с.

Гисматулина Юлия Александровна, кандидат технических наук, младший научный сотрудник лаборатории биоконверсии, Федеральное государственное бюджетное учреждение науки Институт проблем химико-энергетических технологий Сибирского отделения Российской академии наук (ИПХЭТ СО РАН), julja.gismatulina@rambler.ru, тел. (3854) 3059-85. 